OPEN ACCESS

Edited by:

Zhongping Lai,

Shantou University, China

Reviewed by:

Weiming Liu,

Institute of Mountain Hazards and Environment (CAS), China

Fuyuan An,

Qinghai Normal University, China

*Correspondence:

Shengli Yang

shlyang@lzu.edu.cn

Qiong $\mathrm{Li}$

leeqiong@|zu.edu.cn

Specialty section:

This article was submitted to

Quaternary Science, Geomorphology

and Paleoenvironment

a section of the journal

Frontiers in Earth Science

Received: 27 March 2021 Accepted: 01 September 2021 Published: 16 September 2021

Citation:

Yang S, Liu X, Cheng T, Luo Y, Li Q,

Liu $L$ and Chen $Z$ (2021) Stepwise Weakening of Aeolian Activities During the Holocene in the Gannan Region,

Eastern Tibetan Plateau.

Front. Earth Sci. 9:686677.

doi: 10.3389/feart.2021.686677

\section{Stepwise Weakening of Aeolian Activities During the Holocene in the Gannan Region, Eastern Tibetan Plateau}

\author{
Shengli Yang *, Xiaojing Liu, Ting Cheng, Yuanlong Luo, Qiong Li*, Li Liu and Zixuan Chen \\ Key Laboratory of Western China's Environmental Systems (Ministry of Education), College of Earth and Environmental Sciences, \\ Lanzhou University, Lanzhou, China
}

Aeolian sediments hold key information on aeolian history and past environmental changes. Aeolian desertification and extensive land degradation have seriously affected the eco-environment in the Gannan region on the eastern Tibetan Plateau. Understanding the history of aeolian activities can deepen our understanding of the impacts of climatic changes on aeolian activities in the future. This study uses a detailed chronology and multiple proxy analyses of a typical aeolian section in Maqu to reconstruct aeolian activities in the region during the Holocene. Our results showed that aeolian activities have occurred in the eastern Tibetan Plateau since the early Holocene. Magnetic susceptibility, grain size records, and paleosols formation indicated a trend of stepwise weakening in aeolian activities from the early Holocene to the present. The weakening of aeolian activities was divided into three stages: $10.0-8.0 \mathrm{ka} \mathrm{BP}$, $\sim 8.0-4.0 \mathrm{ka} \mathrm{BP}$, and $\sim 4.0 \mathrm{ka} \mathrm{BP}$ to the present. Paleosols were primarily formed after 2.0 ka BP, and episodically interrupted aeolian activities processes in the Gannan region. Aeolian activity may increase in the Gannan region as the climate gradually warms. Climatic changes and local hydrological conditions have jointly affected the history of aeolian activities in this region.

Keywords: loess, sand, aeolian activities, climate change, Holocence

\section{INTRODUCTION}

The Tibetan Plateau (TP) is known as the third pole of the world with the highest altitude (Yao et al., 2012). The TP is a highly unique geological-geographical-ecological unit, with important geographical significance and high sensitivity to global environmental change and human disturbance (Dong et al., 2010; Kang et al., 2010; Chen et al., 2020). The Gannan region is situated on the eastern TP, and is the most important water conservation area in the upper reaches of the Yellow River (Figure 1). In recent decades, accelerating grassland degradation and aeolian desertification have caused severe environmental impacts in the region and its surrounding areas, and as a result, the area has received increased attention (Dong et al., 2010; Shen et al., 2011; You et al., 2014; Cao et al., 2019).

Most studies focus on the effects of modern climate change and human activities on aeolian desertification (Hu et al., 2013; Huo et al., 2013; Hu et al., 2015). However, an understanding of the history and process of desertification in the Gannan region over extended time scales would greatly help to assess the effects of climatic changes on desertification processes. Therefore, investigation of 


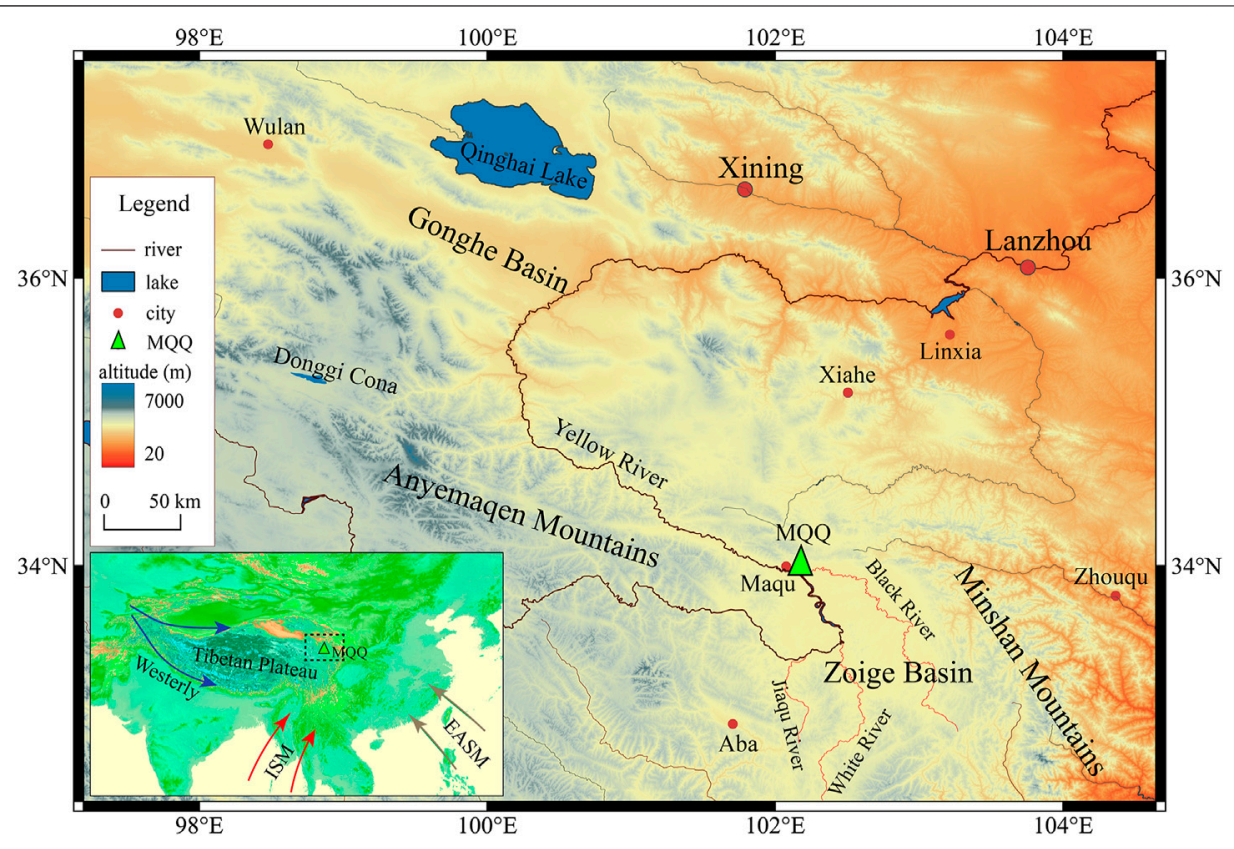

FIGURE 1 | Location of the Maquqiao (MQQ) profile and the terrain of the study area in the eastern Tibetan Plateau. (ISM: India summer monsoon; EASM: East Asian summer monsoon).

the aeolian processes in the Gannan region during the Holocene is essential to better understanding aeolian activities on the TP under global warming (Huo et al., 2013; Hu et al., 2018).

Aeolian sediments are widely distributed in the northeastern $\mathrm{TP}$ and can provide key information on aeolian history and past environmental changes (Stauch et al., 2012; Yu and Lai, 2014; Qiang et al., 2016). The aeolian deposits around Qinghai Lake indicate that aeolian activity and low effective moisture occurred at $\sim 13 \mathrm{ka}, \sim 10-9.1 \mathrm{ka}$, and $\sim 8.9-7.8 \mathrm{ka}$ and that the climate was wetter at $\sim 4-3 \mathrm{ka}$ (Lu et al., 2011). A subsequent study revealed that aeolian activity occurred episodically during the Holocene and that paleosols developed primarily from 9.5 to $4 \mathrm{ka}$ in the Qinghai Lake Basin (Lu et al., 2015). In the Gonghe Basin, Qiang et al. (2013) found that the strongest aeolian activity occurred at 11.8-11.0 ka, $9.4 \mathrm{ka}, 7.8 \mathrm{ka}$, and 5.7 (5.5) ka. The climate records of aeolian deposits reveal a relatively warm and wet climate in the early Holocene, dry conditions from $8.7 \mathrm{ka}$ to $4.7 \mathrm{ka}$, and a warm and wet climate from $4.7 \mathrm{ka}$ to $0.7 \mathrm{ka}$ (Liu et al., 2013a). Aeolian deposition increased significantly in the Donggi Cona catchment during the early Holocene and from 3 ka to the present, which demonstrated that a drier and cooler climate caused the reactivation of dune sand and enhanced aeolian activity during the early Holocene (Stauch et al., 2012). On the basis of a summary of the published optically stimulated luminescence (OSL) ages from the TP, Stauch (2015) suggested that in most regions, the strongest aeolian sediment accumulation occurred during the late Glacial and in the early Holocene, which coincided with the strengthening of the Asian summer monsoon on the TP (Stauch, 2015). However, the history of aeolian activities in different regions is not consistent, and the relationship between aeolian activity and regional evironmental change is likely complex (Qiang et al., 2016).

Few studies have investigated the aeolian history in the Gannan region. Recently, $\mathrm{Hu}$ et al. (2018) analyzed OSL ages from three aeolian sand sections. They found that aeolian activity in the Zoige Basin had occurred since the early Holocene, whereas aeolian sediment deposition primarily had occurred after $\sim 3.20 \pm$ $0.33 \mathrm{ka}$ with a very high sedimentation rate. However, the environmental records of aeolian sediments have not been reconstructed on the basis of detailed geochronology, and further investigations are needed. In this paper, detailed radiocarbon and OSL dating were conducted on a loess-sand profile near Maqu County in the Gannan region to obtain a reliable age framework. Multiple environmental proxies were employed to investigate the history of aeolian activities in the Gannan region and determine its relevance to environmental changes.

\section{GEOGRAPHICAL SETTINGS AND METHODS}

\section{Study Area and Sampling}

The Gannan region, with an altitude of $\sim 3300-4800 \mathrm{~m}$, is situated in the northwest of the Zoige Basin in the eastern TP. It is surrounded by the Anymaqen Mountains to the west, the Minshan Mountains to the east, and the Xiqing Mountains to the north (Figure 1). The Yellow River flows northwest across the basin, and Maqu County is on the north bank. Wide, meandering river valleys of the Yellow River and its tributaries are the main 
A
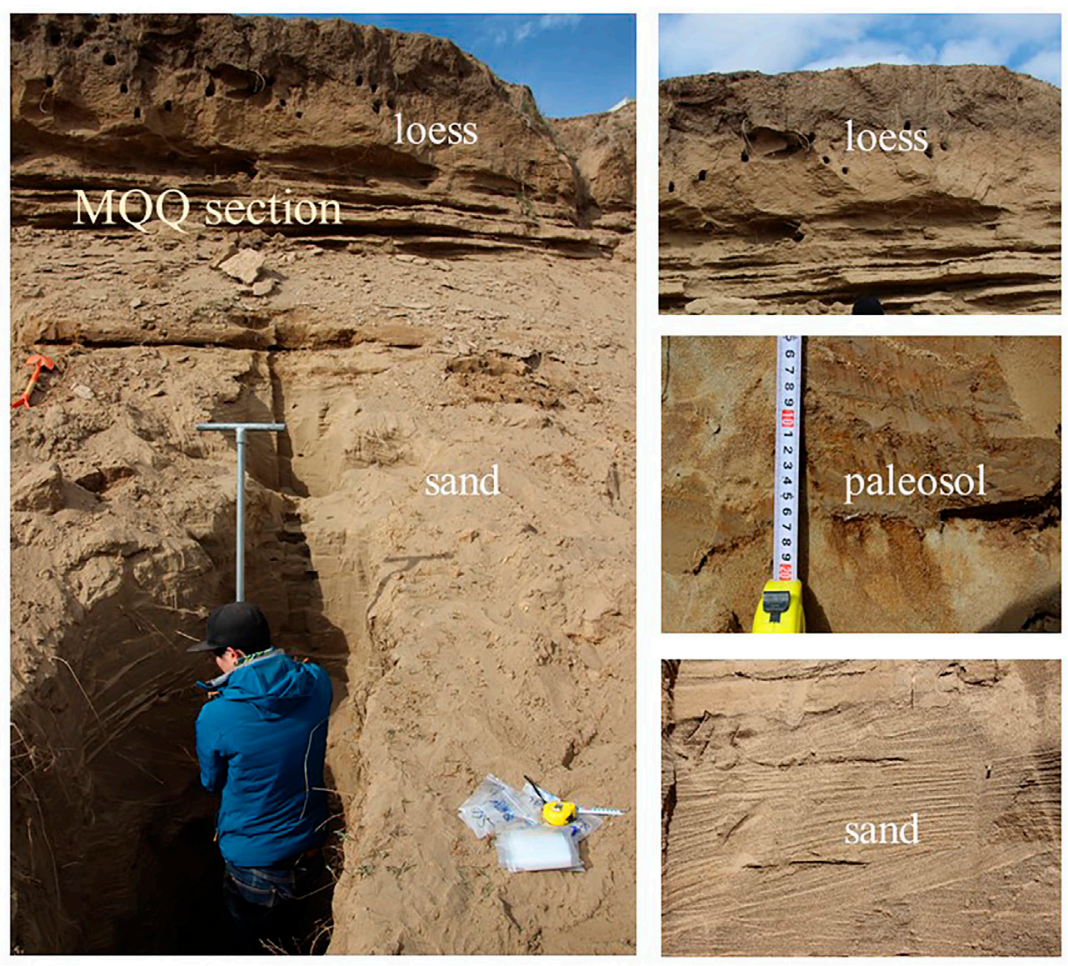

B
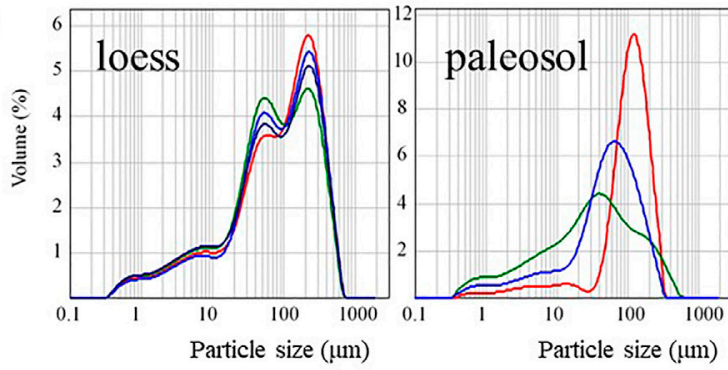

FIGURE 2 | (A) Photographs of the MQQ profile. (B) Grain size distributions in representative samples of loess, paleosol, and aeolian sand from the MQQ profile (different lines in color represent different samples).

rivers around this region, including the White River, the Black River, and Jiaqu River; and this region is the main water supply for the Yellow River (Figure 1). The Gannan region has a continental alpine and humid climate that is mainly affected by the westerlies and the Asian summer monsoon (ASM) (Yao et al., 2012; Yang et al., 2014). The annual average temperature of Maqu County is $1.26^{\circ} \mathrm{C}$, the annual average precipitation is $606.5 \mathrm{~mm}$, and the annual evaporation is $785.9 \mathrm{~mm}$. More than $80 \%$ of the total annual precipitation occurs between May and October due to the influence of the ASM. The vegetation is dominated by alpine shrub meadows and alpine meadows, with mainly alpine meadow soil. Paleo-sand dunes and active dunes are widely distributed in the region. Thin aeolian deposits cover the various terraces and low-relief mountain slopes.

The Maquqiao (MQQ) profile $\left(33.961^{\circ} \mathrm{N}, 102.078^{\circ} \mathrm{E}\right)$ is on the first terrace (T1) of the Yellow River at 3,422 $\mathrm{m}$ a.s.l. (Figure 1), south of Maqu County. The surface of the MQQ profile is $\sim 13 \mathrm{~m}$ above the river level, and is composed of 1.3-m-thick sandy loess at the top and 7.2-m-thick aeolian sands with seven paleosol interbeds in the middle section (Figure 2). The multiple, weak, fine sandy-to-silty paleosol layers of light-grayish color were between 1.7 and $3.5 \mathrm{~m}$. Samples were collected at different depths through the MQQ profile. In the upper 0-4 m, bulk samples for environmental proxies were collected at $2.5-\mathrm{cm}$ intervals. From 4 to $8.5 \mathrm{~m}$, samples were collected at $5-\mathrm{cm}$ intervals because of high deposition rate and no distinct changes. A total of 249 bulk samples were collected, including 197 of sand and 52 of sandy loess. Owing to a lack of charcoal or macrofossils, we collected seven bulk sediments samples along the depth of the MQQ section for accelerator mass spectrometry (AMS) ${ }^{14} \mathrm{C}$ dating. Most samples were taken in or close to the paleosol layers. For the sample at $5 \mathrm{~m}$, we collected bulk sands from the freshly cleaned section for radiocarbon dating. To collect 
TABLE 1 | Accelerator mass spectrometry radiocarbon dating results of the MQQ profile by depth.

\begin{tabular}{|c|c|c|c|c|c|}
\hline Lab. No & Depth(m) & Dating material & Age (cal. BP) & Error $(2 \sigma)$ & Dating lab \\
\hline GN01 & 0.30 & Organic sediments & 388 & 81 & Beta Analytic \\
\hline GNO2 & 1.30 & Organic sediments & 3,098 & 108 & Beta Analytic \\
\hline LZU16026 & 1.95 & Organic sediments & 4,843 & 72 & Peking University \\
\hline GNO3 & 2.20 & Organic sediments & 5,953 & 42 & Beta Analytic \\
\hline LZU16027 & 2.55 & Organic sediments & 7,116 & 197 & Peking University \\
\hline GNO4 & 3.30 & Organic sediments & 5,312 & 187 & Beta Analytic \\
\hline LZU16028 & 5.00 & Organic sediments & 8,387 & 34 & Peking University \\
\hline
\end{tabular}

OSL dating samples, a stainless-steel tube was hammered into a freshly cleaned profile. Three samples were collected and then sealed in black plastic bags to avoid exposure to light.

\section{AMS ${ }^{14} \mathrm{C}$ Dating}

All samples were dried at room temperature before pretreatment. We first removed all rootlets and any visible contaminants from the sample by using tweezers, and then sieved the sediment to $<180$ microns to remove any plant remains or macrofossils. Following this, they were washed with $\mathrm{HCl}$ to remove all carbonates. The remaining samples were then dried at $60^{\circ} \mathrm{C}$ and combusted to extract organic sediment for AMS measurement. Carbon dioxide was obtained by step heating, and was then purified and synthesized into graphite. Four AMS ${ }^{14} \mathrm{C}$ samples were dated at Beta Analytic in Miami, United States, and three others were dated at Peking University in Beijing, China. Ultimately, seven AMS ${ }^{14} \mathrm{C}$ ages were obtained (Table 1).

\section{Optically Stimulated Luminescence Dating}

Three quartz samples were dated by the standard OSL SAR method. The pretreatment and equivalent dose (De) measurements were performed at the Key Laboratory of Western China's Environmental Systems (Ministry of Education), Lanzhou University, Lanzhou, China. All luminescence experimental were conducted in subdued red light. First, wet-sieving was used to separate the $90-125 \mu \mathrm{m}$ size fraction. Then, $\mathrm{HCl}(10 \%)$ was added to remove carbonate, and hydrogen peroxide $(30 \%)$ was added to remove organic matter. The quartz grains were then separated by $2.75 \mathrm{~g} /$ $\mathrm{cm}^{3}$ and $2.62 \mathrm{~g} / \mathrm{cm}^{3}$ sodium polytungstate. Afterward, HF (10\%) was added to etched quartz grains for approximately $40 \mathrm{~min}$ to remove the alpha-irradiated surface layer and weathering products, followed by $\mathrm{HCl}(10 \%)$ for $40 \mathrm{~min}$ to remove fluoride precipitation. The OSL measurements were performed on an automated Risø TL/OSL-20 reader equipped with blue $(470 \mathrm{~nm})$ and infrared $(870 \mathrm{~nm})$ LEDs. The laboratory irradiations were applied using a built-in calibrated ${ }^{90} \mathrm{Sr} /{ }^{90} \mathrm{Y}$ beta source, and the quartz OSL signal was detected using a 7.5-mm Schott U-340 filter. The equivalent dose was determined by using the single-aliquot regenerative-dose (SAR) protocol (Wintle and Murray, 2006), and 12 aliquots were measured for each sample. Some aliquots were omitted in the final calculations of De due to unsatisfactory criteria for the recycling ratio and recuperation. The water content was estimated to be $5 \pm 2 \%$ based on measurement obtained by weighing the samples before and after drying, similar to a previous determination ( $\mathrm{Hu}$ et al., 2018). The concentrations of uranium (U), thorium (Th), potassium $(\mathrm{K})$, and rubidium $(\mathrm{Rb})$ were determined using neutron activation analysis (NAA), and the element results were converted to $\alpha, \beta$, and $\gamma$ dose rates according to the conversion factors (Aitken, 1998).

\section{Environment Proxy Analyses}

Grain size and magnetic susceptibility were measured at the Key Laboratory of Western China's Environmental Systems (Ministry of Education), Lanzhou University. Grain size measurements were conducted on a Malvern Mastersizer 2000 laser diffractometer with a measurement range of $0.02-2,000 \mu \mathrm{m}$. In the pretreatment for grain size measurements, $10 \mathrm{ml}$ of $10 \% \mathrm{H}_{2} \mathrm{O}_{2}$ and $10 \mathrm{ml}$ of $10 \% \mathrm{HCl}$ were used to remove organic matter and carbonate, respectively. Samples were then rinsed with deionized water to remove acid ions. Before measurement, $0.1 \mathrm{~mol} / \mathrm{L}$ $\left(\mathrm{NaPO}_{3}\right)_{6}$ was added, and ultrasonic vibration was used to improve dispersion. Magnetic susceptibility was measured by a Bartington MS2 meter. Air-dried samples were mildly ground and wrapped with plastic film. Then, low frequency $\left(470 \mathrm{~Hz}, \chi_{\mathrm{lf}}\right)$ and high frequency $\left(4,700 \mathrm{~Hz}, \chi_{\mathrm{hf}}\right)$ magnetic susceptibility were measured. The frequency-dependent susceptibility $\left(\chi_{\mathrm{fd}}\right)$ was calculated as $\chi_{\mathrm{fd}}=\chi_{\mathrm{lf}}-\chi_{\mathrm{hf}}$.

\section{RESULTS}

\section{AMS ${ }^{14} \mathrm{C}$ Ages}

Seven samples were collected for AMS ${ }^{14} \mathrm{C}$ dating measurements along the MQQ profile (Figure 3). All calibrated AMS ${ }^{14} \mathrm{C}$ ages are listed in Table 1. The AMS ${ }^{14} \mathrm{C}$ ages ranged from $8,387 \pm$ $34 \mathrm{cal}$. BP to $388 \pm 81 \mathrm{cal}$. BP. Except for the age reversal at $3.30 \mathrm{~m}$, all other AMS ${ }^{14} \mathrm{C}$ ages were consistent with the stratigraphic sequence. Although the AMS ${ }^{14} \mathrm{C}$ results were from two different laboratories, the age results were highly consistent in the stratigraphic sequence, which reflected the reliability of the AMS ${ }^{14} \mathrm{C}$ dating results. Because the age was $8,387 \pm 34 \mathrm{cal}$. BP at the lowest depth of $5 \mathrm{~m}$, and considering that there was $3.5 \mathrm{~m}$ of aeolian sand below, the bottom age of the MQQ profile was inferred to be in the early Holocene. Therefore, according the calibrated $\mathrm{AMS}{ }^{14} \mathrm{C}$ dating, the aeolian sands of the MQQ profile have been deposited at least since the early Holocene, with deposits continuing to the present. The bottom 

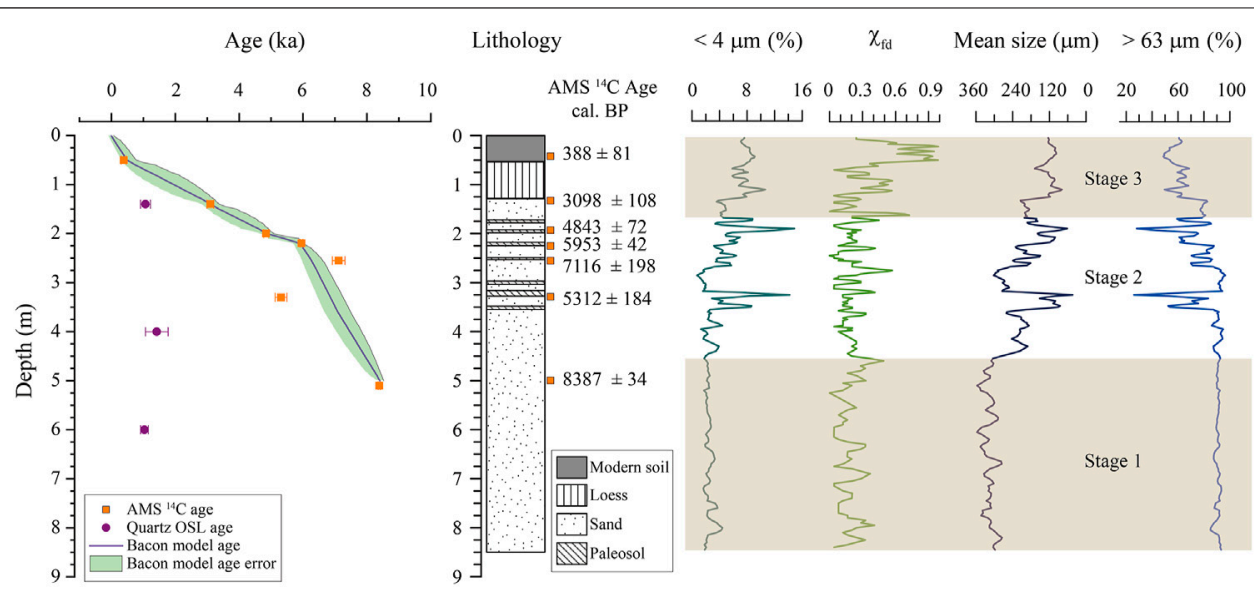

$<4 \mu \mathrm{m}(\%) \quad \chi_{\mathrm{fd}} \quad$ Mean size $(\mu \mathrm{m}) \quad>63 \mu \mathrm{m}(\%)$

FIGURE 3 | Quartz optically stimulated luminescence (optically stimulated luminescence) and accelerator mass spectrometry (AMS) ${ }^{14} \mathrm{C}$ ages and Bacon age-depth model, lithology, grain size records, and the mass-specific frequency-dependent magnetic susceptibility along the depth of the MQQ profile.

TABLE 2| Quartz optically stimulated luminescence (OSL) results at different depths, including equivalent dose (De), overdispersion (OD), contents of U, Th, K, Rb, and water content (WC), dose rate, and quartz OSL ages.

\begin{tabular}{|c|c|c|c|c|c|c|c|c|c|c|c|}
\hline $\begin{array}{l}\text { Depth } \\
\text { (m) }\end{array}$ & $\begin{array}{l}\text { Aliquots } \\
\text { (n) }\end{array}$ & $\begin{array}{l}\text { Grain } \\
\text { size } \\
(\mu \mathrm{m})\end{array}$ & De (Gy) & $\begin{array}{l}\text { OD } \\
(\%)\end{array}$ & $\mathbf{U}(\mathbf{p p m})$ & Th (ppm) & K (\%) & Rb (ppm) & $\begin{array}{l}\text { WC } \\
(\%)\end{array}$ & $\begin{array}{l}\text { Dose } \\
\text { rate } \\
\text { (mGy/yr) }\end{array}$ & $\begin{array}{l}\text { OSL age } \\
\text { (a) }\end{array}$ \\
\hline 1.4 & $9 / 12$ & $90-125$ & $2.52 \pm 0.35$ & $18 \pm 5$ & $1.16 \pm 0.06$ & $6.27 \pm 0.21$ & $1.45 \pm 0.05$ & $59.2 \pm 4.74$ & $5 \pm 2$ & $2.37 \pm 0.07$ & $1,065 \pm 150$ \\
\hline 4.0 & $6 / 12$ & $90-125$ & $2.79 \pm 0.68$ & 0 & $0.99 \pm 0.05$ & $4.95 \pm 0.17$ & $1.23 \pm 0.05$ & $59.2 \pm 4.74$ & $5 \pm 2$ & $1.96 \pm 0.06$ & $1,420 \pm 350$ \\
\hline 6.0 & $10 / 12$ & $90-125$ & $2.50 \pm 0.26$ & 0 & $1.02 \pm 0.05$ & $5.31 \pm 0.18$ & $1.71 \pm 0.05$ & $76.2 \pm 5.33$ & $5 \pm 2$ & $2.42 \pm 0.07$ & $1,035 \pm 115$ \\
\hline
\end{tabular}

age of the sandy loess was 3,098 \pm 108 cal. BP, which implied that there had been a significant weakening in aeolian activity in the Gannan region and a transition from aeolian sand to sandy loess. Thus, the AMS ${ }^{14} \mathrm{C}$ ages produced a reliable age framework for the MQQ profile, and aeolian processes during the Holocene in the Gannan region in the eastern TP could be evaluated (Figure 3).

\section{Quartz Optically Stimulated Luminescence Ages}

Supplementary Figure S1 shows the OSL decay curve and dose response curve of sample MQQ-1. The OSL signals were relatively bright and generally dominated by the fast component decreasing to background within the first $2 \mathrm{~s}$ of stimulation. However, the OSL signals were relatively low, which resulted in a poor signal-to-noise ratio and statistically imprecise doses. The fitted growth curve showed relatively large errors with the measured data points (Supplementary Figure S1). Because of the low overdispersion for all samples, the central age model was used to calculate the final De and apparent OSL ages (Galbraith et al., 1999). The OSL dating results are listed in Table 2. Three ages were obtained: $1,065 \pm 155$ a $(1.4 \mathrm{~m}), 1,420 \pm$ 355 a $(4.0 \mathrm{~m})$, and $1,035 \pm 120$ a (6 m) (Table 2). Thus, all OSL ages were between 1,035 a and 1,420 a, and these OSL ages do not increase with stratigraphic depth. Because the ages at different depths were within a similar range, OSL was not effective for dating the MQQ profile. Compared with the AMS ${ }^{14} \mathrm{C}$ ages, those derived from OSL were significantly younger and were inconsistent with the stratigraphic sequence.

\section{Environmental Proxies}

The particle size distribution characteristics were significantly different among loess, paleosol, and aeolian sand (Figure 2B). The particle size in the aeolian sand samples mainly varied from 0.4 to $600 \mu \mathrm{m}$. The peak size was between 200 and $400 \mu \mathrm{m}$, and the mean size was between 120 and $400 \mu \mathrm{m}$. The particle size in the loess samples varied from 0.2 to $600 \mu \mathrm{m}$. The peak size was between 60 and $300 \mu \mathrm{m}$, and the mean size was between 80 and $200 \mu \mathrm{m}$. The grain size of the paleosol samples varied from 0.2 to $500 \mu \mathrm{m}$. The mode grain size was between 40 and $120 \mu \mathrm{m}$, and the mean size was between 60 and $150 \mu \mathrm{m}$.

Figure 3 shows the change in magnetic susceptibility and particle size with depth in the MQQ profile. The frequency of magnetic susceptibility $\left(\chi_{\mathrm{fd}}\right)$, the fraction $<4 \mu \mathrm{m}$, the mean grain size, and the fraction $>63 \mu \mathrm{m}$ fluctuated significantly with depth (Figure 3). All environmental proxies were divided into two groups with $1.3 \mathrm{~m}$ as the boundary. The $\chi_{\mathrm{fd}}$ values were highest from 0 to $1.3 \mathrm{~m}$, and the average particle size was much finer than that of sands, with abundant clay content and less coarse fraction $>63 \mu \mathrm{m}$. The aeolian sand sediments from 1.3 to $8.5 \mathrm{~m}$ were divided into two groups with $4.8 \mathrm{~m}$ as the boundary. Below $4.8 \mathrm{~m}$, 
the variation in all proxies was relatively low, whereas above $4.8 \mathrm{~m}$, all proxies showed high frequency and large amplitude variations. The $\chi_{\mathrm{fd}}$ values in the paleosol layers of the sand deposits were relatively high but were lower than those in the loess. The fraction $<4 \mu \mathrm{m}$ in the paleosol interlayer within the aeolian sand was significantly higher than that in the aeolian sands, and the corresponding mean grain size and the fraction $>63 \mu \mathrm{m}$ were distinctly lower. Thus, grain size and magnetic susceptibility were good indicators of changes in the environment in both aeolian sand and loess deposits.

\section{DISCUSSION}

\section{Timing of Aeolian Activities in the Gannan Region}

For the MQQ section, the quartz OSL dating yielded significantly younger ages than those of AMS ${ }^{14} \mathrm{C}$. Moreover, all OSL ages were concentrated between 1,035 and 1,420 a without stratigraphic order. By contrast, AMS ${ }^{14} \mathrm{C}$ dating results showed good stratigraphic order with depth in the MQQ profile with ages ranging from $388 \pm 31$ to $8,387 \pm 34 \mathrm{cal}$. BP. However, there was a significant reversal at $3.3 \mathrm{~m}$. The comparison of OSL and AMS ${ }^{14} \mathrm{C}$ ages showed that the luminescence ages were significant underestimations.

OSL dating is usually an effective dating method for aeolian deposits, but its reliability can be affected by a variety of factors, such as dim OSL signals and post-depositional disturbance (Bateman et al., 2003; Bateman et al., 2007; Ahr et al., 2013). The relatively low quartz OSL signals with poor signal-to-noise ratios likely led to the large uncertainties in the Des (Supplementary Figure S1). According to eleven quartz OSL ages of three aeolian sections in this region, the oldest OSL age of aeolian sands is $10.27 \pm 0.81 \mathrm{ka}$ (Hu et al., 2018). However, most of the OSL ages are younger than $3.32 \pm 0.33 \mathrm{ka}$, indicating a high accumulation rate (Hu et al., 2018). Considering the depths of the two OSL ages of $10.27 \pm 0.81 \mathrm{ka}$ and $3.07 \pm 0.30 \mathrm{ka}$ from Section 1 (1.5 $\mathrm{m}$ deep) in Hu et al., 2018, there may exist an erosion hiatus at this site. Although detailed information is lacking, in Section 3 ( $4 \mathrm{~m}$ deep), the OSL age estimates ranged from 0.17 to $0.92 \mathrm{ka}$ (Hu et al., 2018), and were close to our OSL results in this study. Moreover, many rodent burrows were observed along the MQQ profile (Figure 2A). Rodent activities can cause varying degrees of mixing of sediments, resulting in an underestimation of the OSL age (Bateman et al., 2007; Ahr et al., 2013). Thus, the significant underestimation of OSL ages might have been caused by postdeposition biological disturbances. Therefore, the three OSL results of the MQQ profile did not indicate its true stratigraphic age because of large uncertainties and underestimated ages. The concentration of the three OSL ages in the range of 1,035 a to 1,420 a might indicate a rodent-active period. Rodent activity remains prevalent in alpine pastures in the Gannan region, with its effects having appeared since at least 1,035 a to 1,420 a. However, further evaluations of OSL dating in this region are needed.

Owing to a lack of charcoal or macrofossils along the MQQ section, we used organic sediments for radiocarbon dating. Previous studies have shown that the dating of bulk organic matter of aeolian loess can yield a reliable AMS ${ }^{14} \mathrm{C}$ age for the past $25 \mathrm{cal} \mathrm{kyr} \mathrm{BP}$ (Song et al., 2018; Cheng et al., 2020). Only one radiocarbon age at $3.3 \mathrm{~m}$ was out of line with the stratigraphic order, showing younger ages than its upper sample. This might have resulted from young carbon contaminations or postdeposition mixing. Most of the AMS ${ }^{14} \mathrm{C}$ samples were collected in paleosol layers that were relatively stable, whereas the OSL samples were taken from aeolian sand layers. As a result, bioturbation likely had greater effects on the OSL results than on those of AMS ${ }^{14} \mathrm{C}$ dating. In addition, the results from the two laboratories were in good agreement, which also illustrates the reliability of AMS dating (Table 1). According to the AMS ${ }^{14} \mathrm{C}$ results and field observations, no prominent sedimentary hiatus was identified in the Maqu section. Thus, the results of AMS ${ }^{14} \mathrm{C}$ dating with good stratigraphic order were used to build the age control for the MQQ section.

Based on AMS ${ }^{14} \mathrm{C}$ results, the Bacon software package was used to establish a Bayesian-based age-depth model for the upper $5 \mathrm{~m}$ of the MQQ profile (Blaauw and Christen, 2011) (Figure 3). The Bacon model converted depth into a time scale (Figure 4). The age of the bottom of the MQQ profile at a depth of $5 \mathrm{~m}$ was $8,387 \pm 34$ a BP. According to the results of the Bacon age-depth model and considering an average accumulation rate of $2.2-5.0 \mathrm{~m}$ of aeolian sand, the estimated age at the bottom of the MQQ profile was approximately $11 \mathrm{ka}$ in the early Holocene. This result showed that aeolian sand activities in the Gannan region have occurred since the early Holocene and continued to the late Holocene. Moreover, multiple paleosol interlayers occurring episodically among the aeolian sands indicated that soil formation processes during humid stages punctuated the aeolian sand activity (Stauch, 2015).

Variations in climate and local hydrological conditions might jointly have influenced the history of aeolian activity in the region. Previous studies have found that significant accumulation of aeolian sediments in the northeastern TP began in the early Holocene (Lu et al., 2011; Qiang et al., 2013; Stauch, 2015). Drilling records of the Zoige Basin demonstrate that it was a paleo lake before the Holocene and that it began to dry out gradually between 40 and $22 \mathrm{ka}$ (Wang et al., 1995). According to OSL dating, aeolian sand around the Zoige Basin was not deposited earlier than the early Holocene, and aeolian deposition primarily occurred in the late Holocene (Hu et al., 2018). The shrinkage and disappearance of ancient lakes provide abundant supplies of sediments, and in addition to climate warming in the early Holocene, may have led to enhanced aeolian activities in the Gannan region.

\section{Stepwise Weakening of Aeolian Activities During the Holocene}

The mass-specific frequency-dependent susceptibility $\left(\chi_{\mathrm{fd}}\right)$ is an important indicator of pedogenesis-related effective moisture in aeolian deposits (Kukla et al., 1988; Zhou et al., 1990; An et al., 1991; Liu et al., 2004). Grain size is an important environmental indicator of paleoclimate, especially for aeolian sediments (Vandenberghe et al., 1997; Sun et al., 2002; Prins et al., 2007). The $\chi_{\mathrm{fd}}$ and the mean grain size records showed clear upward, 
Age (ka)

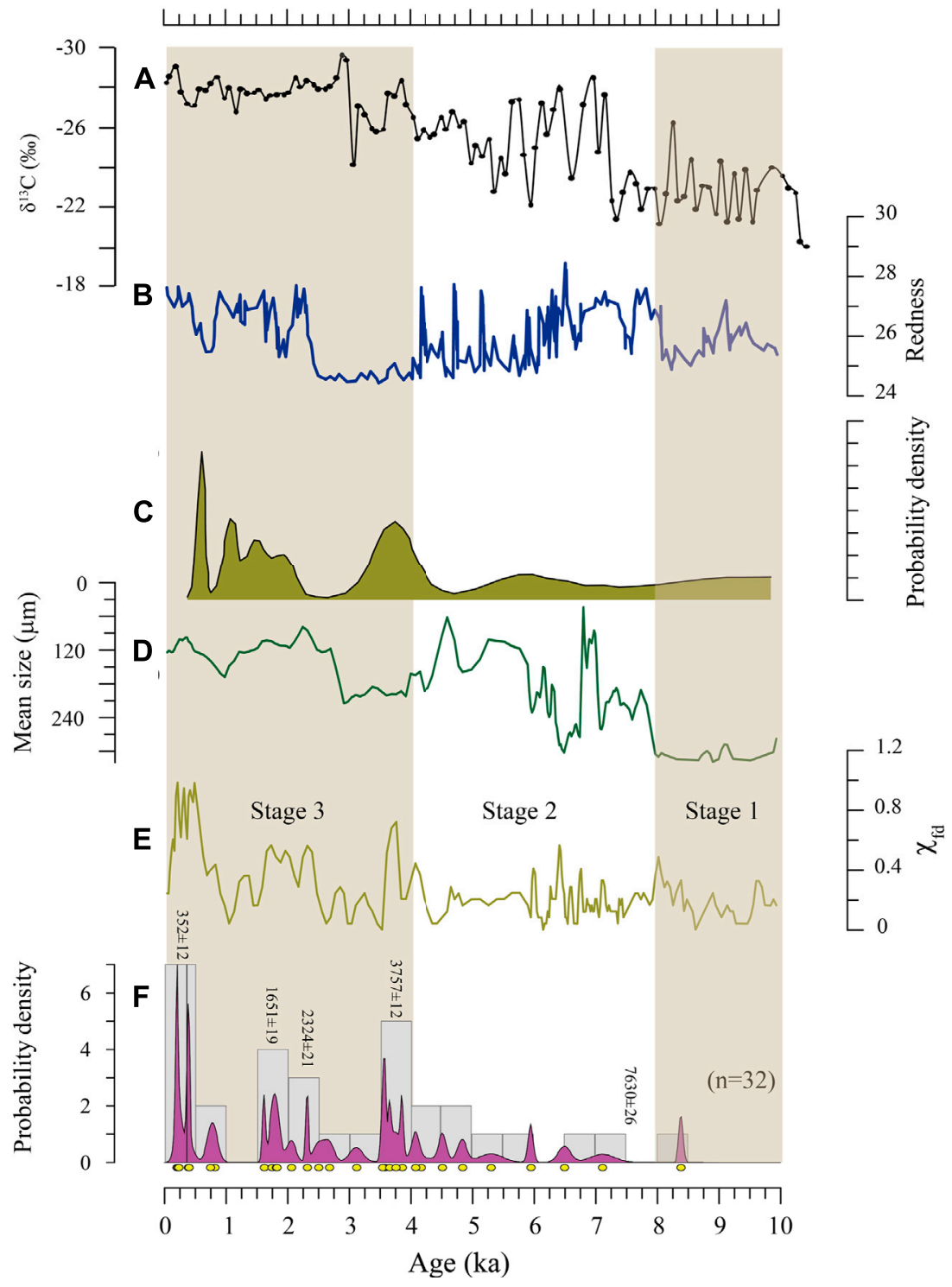

FIGURE 4 | (A) Organic $\delta^{13} \mathrm{C}$ records indicating the variation in water depth (Liu et al., 2013b) and (B) Redness-inferred precipitation at Qianghai Lake (Ji et al., 2005). (C) OSL ages probability density for sandy loess from the Anyemaqen Mountains (Stauch, 2015). (D) Mean grain size and (E) Mass-specific frequency-dependent susceptibility $\left(\chi_{\mathrm{fd}}\right)$ from the MQQ profile. (F) Probability density function of radio carbon ages for paleosols since the early Holocene in the eastern Tibetan Plateau. Radio carbon ages of paleosols are from (Xu, 1994; Zou and Wang, 1995; Fang et al., 1998; He et al., 2006; Lehmkuhl et al., 2014; Hu et al., 2016), and this study.

increasing trends, which indicated a stepwise wetting history since the early Holocene to the present (Figure 4). The process was divided into three steps based on the grain size and $\chi_{\text {fd }}$ records: $\sim 10.0-8.0 \mathrm{ka}, \sim 8.0-4.0 \mathrm{ka}$, and $\sim 4.0 \mathrm{ka}$ to the present (Figure 4). Most multiple paleosol interlayers of the MQQ section occurring after $8 \mathrm{ka}$ also implied a trend of wetting in the Gannan region (Figure 3). Aeolian sands represent the expansion and accumulation of aeolian landforms, whereas paleosols are an indication of the stability of aeolian landforms, accompanied by increases in vegetation cover. Therefore, aeolian sediments and the formation of paleosols indicate dry and wet phases, respectively (Stauch, 2015). The probability density function (PDF) was calculated, and each age was regarded as an individual accumulation event (Lai et al., 2009; Stauch, 2015). The PDF of radiocarbon ages of paleosols around the Gannan region can reflect the periods of paleosol development. Paleosols were formed mainly after $\sim 8.0 \mathrm{ka}$ and indicated increasing effective moisture and episodic interruptions of aeolian desertification processes in the eastern TP (Figure 4F). The proxy records in this study agree well with the aeolian activities indicated by the probability density of OSL ages of aeolian sediments from the northeastern TP and 
Anyemaqen Mountain area (Figure 4C) (Stauch, 2015) and by the organic $\delta^{13} \mathrm{C}$ records indicating variation in water depth and the redness-inferred precipitation at Qinghai Lake (Figures 4A,B) (Ji et al., 2005; Liu et al., 2013b).

Based on the records in this study, the stepwise weakening of aeolian activities was divided into three stages that coincided with increasing moisture since the early Holocene (Figure 4). In stage $1(\sim 10-8.0 \mathrm{ka} \mathrm{BP})$, according to AMS ${ }^{14} \mathrm{C}$ dating, the age in the MQQ profile was approximately $8 \mathrm{ka} B P$ at $5 \mathrm{~m}$ and approximately $11 \mathrm{ka}$ at the bottom. Coarse grain size and rare paleosol development implied strong aeolian activities with strengthened winds and suggested that aeolian activity in the Gannan region occurred at least since the early Holocene. This result is consistent with previous results in this region and the northeastern TP (Lu et al., 2011; Stauch et al., 2012; Qiang et al., 2013; Chen et al., 2016). The level of the lake was low and the climate was very dry in basins in the northeastern TP during the early to middle Holocene (Chen et al., 2016; Wu et al., 2020). In the Gonghe Basin in the northwest of the Gannan region, aeolian activity had occurred from 11.8 to $11.0 \mathrm{ka}$ and at approximately $9.4 \mathrm{ka}$ (Qiang et al., 2013); and in the Donggi Cona catchment to the west of the Gannan region, aeolian activity began at $\sim 10.5 \mathrm{ka}$ (Stauch et al., 2012). Strong aeolian activity in the early Holocene has also been reported in Qinghai Lake and the Qaidam Basin (Lu et al., 2011; Yu and Lai, 2014).

Stage 2 ( 8.0-4.0 ka BP) corresponded to the mid-Holocene. Compared with the first stage in the early Holocene, the $\chi \mathrm{fd}$ value increased and the mean grain size decreased. Moreover, multiple, weak fine sand to silty paleosol layers were formed during this stage, indicating relatively wet climate conditions. Therefore, the aeolian activity weakened, and sand accumulation was interrupted by pedogenesis due to increases in humidity. Other studies also report a relatively warmer and wetter climate in the mid-Holocene in the northeastern TP (An et al., 2006; Stauch, 2015; Li et al., 2017; Wei et al., 2020). Loess records from the southern Anyemaqen Mountains indicate the climate was relatively humid from 8 to $4 \mathrm{ka}$, and the formation of a distinct paleosol layer also implied more humid conditions than those in the early Holocene (Lehmkuhl et al., 2014). The pollen record indicated that the precipitation in the northern TP reached a maximum in the mid-Holocene ( $\mathrm{Li}$ et al., 2017). Pollen records also reveal a strong summer monsoon in the mid-Holocene (Wei et al., 2020) and extensive paleosol development from 5 to $3 \mathrm{ka}$ (Yang et al., 2019).

In stage $3(\sim 4.0 \mathrm{ka}$ to the present), the weakest aeolian activity during the Holocene occurred. From 4.0 ka to the present, the $\chi_{\mathrm{fd}}$ value generally increased and the mean grain size decreased, which demonstrated the enhanced precipitation and weakened wind circulation. A permanent shift from aeolian sands to loess deposits occurred at the MQQ, implying a further weakening of aeolian activity (Figure 4). A similar shift to a more humid climate was found in the northern TP (Stauch et al., 2017). The local topographic position has an important influence on loess and sand deposits (Stauch et al., 2017). Aeolian sand continued to be deposited on other suitable sites in this stage (Hu et al., 2018). Loess sediments on the TP are normally associated with a wetter climate, because in a humid climate, vegetation density increases and more silty sediments are trapped (Lu et al., 2011; Stauch, 2015).
With increasing rainfall, the level of the lake rose, and the surface wind-sand supplies decreased largely owing to better vegetation fixation and soil development. Thus, there was a transition from wind-sand deposits to loess deposits in the Maqu region. This wetting trend of the climate also occurred in the surrounding areas. The level of the lake was higher than that in the early to midHolocene (Chen et al., 2016), and a humid period occurred from 4 to $3 \mathrm{ka}$ in the Qinghai Lake Basin (Lu et al., 2011). The Gonghe Basin was warmer and wetter from 4.7 to $0.7 \mathrm{ka}$ than in the midHolocene (Liu et al., 2013a). Intensified agricultural cultivation since $2.2 \mathrm{ka}$ in the Qinghai Lake basin also indicates the climate was humid during the late Holocene (Wei et al., 2020). Therefore, loess accumulation at this time can be linked to increased vegetation cover acting as a sediment trap (Chen et al., 2020).

However, some studies suggest that the climate became dry again in the late Holocene and that aeolian activities strengthened again in the northeastern TP (Stauch et al., 2012; Lu et al., 2015; Stauch, 2015). These contradictions suggest that the history of aeolian activities in different regions is inconsistent, which may reflect the complex responses of different regions to climate change (Qiang et al., 2013; Lu et al., 2015). In addition, the Yellow River catchment could have greatly affected aeolian activities because of changes in sand supply and landforms. The Zoige Basin was infilled with plenty of fluvial-lacustrine sediments, and the abundant finegrained materials were susceptible to deflation and redeposition. The shrinking of the river system and lakes in the northeastern TP significantly affected aeolian activities by increasing material supplies. Therefore, climate change and regional response together determined the history of wind-sand activities in the region. The stepwise weakening of aeolian activities in the eastern $\mathrm{TP}$ might have been caused by variations in climate and local hydrological conditions (Qiang et al., 2016; Stauch et al., 2017; Hu et al., 2018). Further investigations in a broader region are needed.

The stacked global paleotemperature demonstrated that the global annual temperature had reached a maximum in the early Holocene, and then had decreased through the middle to late Holocene (Marcott et al., 2013). The Gannan region is located in the eastern TP, where precipitation is mainly controlled by the ASM (Chen et al., 2020; Zhao et al., 2020). Peat sediment records suggest that the climate remained warm/wet during the early to mid-Holocene, and became relatively cold/dry in the late Holocene (Yu et al., 2006; Sun et al., 2017). The strong aeolian activities related to the high aridity of the early to middle Holocene in the Maqu area could have been caused by higher summer temperatures that drove enhanced evaporation (Wu et al., 2020). Climatic warming-enhanced evaporation has caused an enormous loss of water in the basins of the northeastern TP (Wu et al., 2016). Similar to the strong aeolian activities in the warm early Holocene, even if the precipitation increases, future global warming will enhance aeolian activities in the eastern TP.

In summary, a stepwise weakening in aeolian activities has occurred since the early Holocene in the Gannan region. Extreme aeolian sands were deposited mainly under the warm climate in the early to mid-Holocene, whereas the weakest deposition occurred after $4.0 \mathrm{ka}$. The history of aeolian activity was mainly controlled by climate change since the Holocene, but was also affected by the local geomorphology and regional 
hydrological conditions. The results of this study show that the relations between aeolian activity and regional climate change are complex. Future global warming could lead to increases in aeolian activities similar to those that occurred in the early Holocene.

\section{CONCLUSION}

In this study, detailed chronology and multiple proxy analyses were conducted on an MQQ aeolian section and used to reconstruct the history of aeolian activities during the Holocene in the eastern TP. Aeolian activities have occurred since the warm early Holocene in the eastern TP. Magnetic susceptibility, grain size records, and paleosol formation indicated a stepwise weakening in aeolian activities from the early Holocene to the present. The weakening of aeolian activities was divided into three stages: $\sim 10.0-8.0 \mathrm{ka} \mathrm{BP}, \sim 8.0-4.0 \mathrm{ka} \mathrm{BP}$, and $\sim 4.0 \mathrm{ka} \mathrm{BP}$ to the present. Paleosols were formed primarily after $\sim 8.0 \mathrm{ka} \mathrm{BP}$ and indicated episodic interruptions of aeolian desertification in the Gannan region. The results indicate that aeolian activity may increase in the Gannan region as the climate gradually warms. Variations in the Asian summer monsoon and local hydrological conditions may have caused environmental changes in the eastern TP. These results strengthen the understanding of the evolution of aeolian activities in the eastern TP.

\section{DATA AVAILABILITY STATEMENT}

The raw data supporting the conclusions of this article will be made available by the authors, without undue reservation.

\section{REFERENCES}

Ahr, S. W., Nordt, L. C., and Forman, S. L. (2013). Soil Genesis, Optical Dating, and Geoarchaeological Evaluation of Two upland Alfisol Pedons within the Tertiary Gulf Coastal Plain. Geoderma 192, 211-226. doi:10.1016/j.geoderma.2012.08.016

Aitken, M. J. (1998). An Introduction to Optical Dating. Oxford, UK: Oxford University Press.

An, C.-B., Feng, Z.-D., and Barton, L. (2006). Dry or Humid? Mid-holocene Humidity Changes in Arid and Semi-arid China. Quat. Sci. Rev. 25, 351-361. doi:10.1016/j.quascirev.2005.03.013

An, Z., Kukla, G. J., Porter, S. C., and Xiao, J. (1991). Magnetic Susceptibility Evidence of Monsoon Variation on the Loess Plateau of central China during the Last 130,000 Years. Quat. Res. 36, 29-36. doi:10.1016/0033-5894(91) 90015-w

Bateman, M. D., Boulter, C. H., Carr, A. S., Frederick, C. D., Peter, D., and Wilder, M. (2007). Detecting post-depositional Sediment Disturbance in sandy Deposits Using Optical Luminescence. Quat. Geochronol. 2, 57-64. doi:10.1016/j.quageo.2006.05.004

Bateman, M. D., Frederick, C. D., Jaiswal, M. K., and Singhvi, A. K. (2003). Investigations into the Potential Effects of Pedoturbation on Luminescence Dating. Quat. Sci. Rev. 22, 1169-1176. doi:10.1016/s0277-3791(03)00019-2

Blaauw, M., and Christen, J. A. (2011). Flexible Paleoclimate Age-Depth Models Using an Autoregressive Gamma Process. Bayesian Anal. 6, 457-474. doi:10.1214/ba/1339616472

Cao, J., Adamowski, J. F., Deo, R. C., Xu, X., Gong, Y., and Feng, Q. (2019). Grassland Degradation on the Qinghai-Tibetan Plateau: Reevaluation of Causative Factors. Rangeland Ecol. Manage. 72, 988-995. doi:10.1016/ j.rama.2019.06.001

\section{AUTHOR CONTRIBUTIONS}

SY and QL designed the study. SY, TC YL, LL, and ZC, carried out field work and collected samples. XL, TC, and LL performed laboratory analysis. SY, QL, and XL performed data interpretations. SY, XL, and QL wrote the manuscript. All authors discussed interpretations and commented on the manuscript.

\section{FUNDING}

This work was supported by the National Natural Science Foundation of China $(41877447,41472147)$, the Strategic Priority Research Program of the Chinese Academy of Sciences (XDA20090003), and the Fundamental Research Funds for the Central Universities (lzujbky-2015-k10; lzujbky2015-bt01).

\section{ACKNOWLEDGMENTS}

We thank X. Meng, D. Yue, M. Liang, S. Li, and D. Li for their assistance in the field and with sample preparation.

\section{SUPPLEMENTARY MATERIAL}

The Supplementary Material for this article can be found online at: https://www.frontiersin.org/articles/10.3389/feart.2021.686677/ full\#supplementary-material

Chen, F., Wu, D., Chen, J., Zhou, A., Yu, J., Shen, J., et al. (2016). Holocene Moisture and East Asian Summer Monsoon Evolution in the Northeastern Tibetan Plateau Recorded by Lake Qinghai and its Environs: A Review of Conflicting Proxies. Quat. Sci. Rev. 154, 111-129. doi:10.1016/ j.quascirev.2016.10.021

Chen, F., Zhang, J., Liu, J., Cao, X., Hou, J., Zhu, L., et al. (2020). Climate Change, Vegetation History, and Landscape Responses on the Tibetan Plateau during the Holocene: A Comprehensive Review. Quat. Sci. Rev. 243, 106444. doi:10.1016/j.quascirev.2020.106444

Cheng, P., Burr, G. S., Zhou, W., Chen, N., Hou, Y., Du, H., et al. (2020). The Deficiency of Organic Matter 14C Dating in Chinese Loess-Paleosol Sample. Quat. Geochronol. 56, 101051. doi:10.1016/j.quageo.2019.101051

Dong, Z., Hu, G., Yan, C., Wang, W., and Lu, J. (2010). Aeolian Desertification and its Causes in the Zoige Plateau of China's Qinghai-Tibetan Plateau. Environ. Earth Sci. 59, 1731-1740. doi:10.1007/s12665-009-0155-9

Fang, X., Li, J., Zhou, S., and Kang, S. (1998). Aeolian Sand Deposition in the Source Area of Yellow River and its Significance. Acta Sedimentologica Sinica 16, 40-44. doi:10.14027/j.cnki.cjxb.1998.01.007

Galbraith, R. F., Roberts, R. G., Laslett, G. M., Yoshida, H., and Olley, J. M. (1999). Optical Dating of Single and Multiple Grains of Quartz from Jinmium Rock Shelter, Northern Australia: Part I, Experimental Design and Statistical Models. Archaeometry 41, 339-364. doi:10.1111/j.1475-4754.1999.tb00987.x

He, W., Xiong, Z., Yuan, D., Ge, W., and Liu, X. (2006). Palaeo-earthquake Study on the Maqu Fault of East Kunlun Active Fault. Earthquake Res. China 22, 126-134. doi:10.3969/j.issn.1001-4683.2006.02.002

Hu, G., Dong, Z., Lu, J., and Yan, C. (2015). The Developmental Trend and Influencing Factors of Aeolian Desertification in the Zoige Basin, Eastern Qinghai-Tibet Plateau. Aeolian Res. 19, 275-281. doi:10.1016/ j.aeolia.2015.02.002 
Hu, G., Jin, H., Dong, Z., Lu, J., and Yan, C. (2013). Driving Forces of Aeolian Desertification in the Source Region of the Yellow River: 1975-2005. Environ. Earth Sci. 70, 3245-3254. doi:10.1007/s12665-013-2389-9

Hu, G., Yu, L., Dong, Z., Lu, J., Li, J., Wang, Y., et al. (2018). Holocene Aeolian Activity in the Zoige Basin, Northeastern Tibetan Plateau, China. CATENA 160, 321-328. doi:10.1016/j.catena.2017.10.005

Hu, M., Zuo, H., Pang, N., and Li, X. (2016). Evolution of Chemical Weathering Process since the Middle-Late Holocene in the Maqu Plateau. J. Desert Res. 36, 623-635.

Huo, L., Chen, Z., Zou, Y., Lu, X., Guo, J., and Tang, X. (2013). Effect of Zoige alpine Wetland Degradation on the Density and Fractions of Soil Organic Carbon. Ecol. Eng. 51, 287-295. doi:10.1016/ j.ecoleng.2012.12.020

Ji, J., Shen, J., Balsam, W., Chen, J., Liu, L., and Liu, X. (2005). Asian Monsoon Oscillations in the Northeastern Qinghai-Tibet Plateau since the Late Glacial as Interpreted from Visible Reflectance of Qinghai Lake Sediments. Earth Planet. Sci. Lett. 233, 61-70. doi:10.1016/j.epsl.2005.02.025

Kang, S., Xu, Y., You, Q., Flügel, W.-A., Pepin, N., and Yao, T. (2010). Review of Climate and Cryospheric Change in the Tibetan Plateau. Environ. Res. Lett. 5, 015101. doi:10.1088/1748-9326/5/1/015101

Kukla, G., Heller, F., Ming, L., Chun, X., Sheng, L., and Sheng, A. (1988). Pleistocene Climates in China Dated by Magnetic Susceptibility. Geology 16 (9), 811. doi:10.1130/0091-7613(1988)016<0811:pcicdb >2.3.co;2

Lai, Z., Kaiser, K., and Brückner, H. (2009). Luminescence-dated Aeolian Deposits of Late Quaternary Age in the Southern Tibetan Plateau and Their Implications for Landscape History. Quat. Res. 72, 421-430. doi:10.1016/j.yqres.2009.07.005

Lehmkuhl, F., Schulte, P., Zhao, H., Hülle, D., Protze, J., and Stauch, G. (2014). Timing and Spatial Distribution of Loess and Loess-like Sediments in the Mountain Areas of the Northeastern Tibetan Plateau. CATENA 117, 23-33. doi:10.1016/j.catena.2013.06.008

Li, J., Dodson, J., Yan, H., Cheng, B., Zhang, X., Xu, Q., et al. (2017). Quantitative Precipitation Estimates for the Northeastern Qinghai-Tibetan Plateau over the Last 18,000 Years. J. Geophys. Res. Atmos. 122, 5132-5143. doi:10.1002/ 2016jd026333

Liu, B., Jin, H., Sun, L., Sun, Z., Su, Z., and Zhang, C. (2013a). Holocene Climatic Change Revealed by Aeolian Deposits from the Gonghe Basin, Northeastern Qinghai-Tibetan Plateau. Quat. Int. 296, 231-240. doi:10.1016/ j.quaint.2012.05.003

Liu, Q., Jackson, M. J., Banerjee, S. K., Maher, B. A., Deng, C., Pan, Y., et al. (2004). Mechanism of the Magnetic Susceptibility Enhancements of the Chinese Loess. J. Geophys. Res. Solid Earth 109. doi:10.1029/2004jb003249

Liu, W., Li, X., An, Z., Xu, L., and Zhang, Q. (2013b). Total Organic Carbon Isotopes: A Novel Proxy of lake Level from Lake Qinghai in the Qinghai-Tibet Plateau, China. Chem. Geology 347, 153-160. doi:10.1016/j.chemgeo.2013.04.009

Lu, R., Jia, F., Gao, S., Shang, Y., Li, J., and Zhao, C. (2015). Holocene Aeolian Activity and Climatic Change in Qinghai Lake basin, Northeastern QinghaiTibetan Plateau. Palaeogeogr. Palaeoclimatol. Palaeoecol. 430, 1-10. doi:10.1016/j.palaeo.2015.03.044

Lu, H. Y., Zhao, C. F., Mason, J., Yi, S. W., Zhao, H., Zhou, Y. L., et al. (2011). Holocene Climatic Changes Revealed by Aeolian Deposits from the Qinghai Lake Area (Northeastern Qinghai-Tibetan Plateau) and Possible Forcing Mechanisms. Holocene 21, 297-304. doi:10.1177/0959683610378884

Marcott, S. A., Shakun, J. D., Clark, P. U., and Mix, A. C. (2013). A Reconstruction of Regional and Global Temperature for the Past 11,300 Years. science 339, 1198-1201. doi:10.1126/science. 1228026

Prins, M. A., Vriend, M., Nugteren, G., Vandenberghe, J., Lu, H., Zheng, H., et al. (2007). Late Quaternary Aeolian Dust Input Variability on the Chinese Loess Plateau: Inferences from Unmixing of Loess Grain-Size Records. Quat. Sci. Rev. 26, 230-242. doi:10.1016/j.quascirev.2006.07.002

Qiang, M., Chen, F., Song, L., Liu, X., Li, M., and Wang, Q. (2013). Late Quaternary Aeolian Activity in Gonghe Basin, Northeastern QinghaiTibetan Plateau, China. Quat. Res. 79, 403-412. doi:10.1016/ j.yqres.2013.03.003

Qiang, M., Jin, Y., Liu, X., Song, L., Li, H., Li, F., et al. (2016). Late Pleistocene and Holocene Aeolian Sedimentation in Gonghe Basin, Northeastern QinghaiTibetan Plateau: Variability, Processes, and Climatic Implications. Quat. Sci. Rev. 132, 57-73. doi:10.1016/j.quascirev.2015.11.010
Shen, M., Tang, Y., Chen, J., Zhu, X., and Zheng, Y. (2011). Influences of Temperature and Precipitation before the Growing Season on spring Phenology in Grasslands of the central and Eastern Qinghai-Tibetan Plateau. Agric. For. Meteorology 151, 1711-1722. doi:10.1016/ j.agrformet.2011.07.003

Song, Y., Luo, D., Du, J., Kang, S., Cheng, P., Fu, C., et al. (2018). Radiometric Dating of Late Quaternary Loess in the Northern piedmont of South Tianshan Mountains: Implications for Reliable Dating. Geol. J. 53, 417-426. doi:10.1002/ gj.3129

Stauch, G. (2015). Geomorphological and Palaeoclimate Dynamics Recorded by the Formation of Aeolian Archives on the Tibetan Plateau. Earth-Science Rev. 150, 393-408. doi:10.1016/j.earscirev.2015.08.009

Stauch, G., Ijmker, J., Pötsch, S., Zhao, H., Hilgers, A., Diekmann, B., et al. (2012). Aeolian Sediments on the north-eastern Tibetan Plateau. Quat. Sci. Rev. 57, 71-84. doi:10.1016/j.quascirev.2012.10.001

Stauch, G., Schulte, P., Ramisch, A., Hartmann, K., Hülle, D., Lockot, G., et al. (2017). Landscape and Climate on the Northern Tibetan Plateau during the Late Quaternary. Geomorphology 286, 78-92. doi:10.1016/ j.geomorph.2017.03.008

Sun, D., Bloemendal, J., Rea, D. K., Vandenberghe, J., Jiang, F., An, Z., et al. (2002). Grain-size Distribution Function of Polymodal Sediments in Hydraulic and Aeolian Environments, and Numerical Partitioning of the Sedimentary Components. Sediment. Geology 152, 263-277. doi:10.1016/s0037-0738(02) $00082-9$

Sun, X., Zhao, Y., and Li, Q. (2017). Holocene Peatland Development and Vegetation Changes in the Zoige Basin, Eastern Tibetan Plateau. Sci. China Earth Sci. 60, 1826-1837. doi:10.1007/s11430-017-9086-5

Vandenberghe, J., An, Z. S., Nugteren, G., Lu, H., and Van Huissteden, K. (1997). New Absolute Time Scale for the Quaternary Climate in the Chinese Loess Region by Grain-Size Analysis. Geology 25, 35. doi:10.1130/0091-7613(1997) 025<0035:natsft $>2.3 . c 0 ; 2$

Wang, Y. F., Wang, S. M., Xue, B., Ji, L., Wu, J. L., Xia, W. L., et al. (1995). Sedimentological Evidence of the Piracy of Fossil Zoige lake by the Yellow-River. Chin. Sci. Bull. 40, 1539-1544. doi:10.1360/csb1995-408-723

Wei, H., E, C., Zhang, J., Sun, Y., Li, Q., Hou, G., et al. (2020). Climate Change and Anthropogenic Activities in Qinghai Lake Basin over the Last 8500 Years Derived from Pollen and Charcoal Records in an Aeolian Section. CATENA 193, 104616. doi:10.1016/j.catena.2020.104616

Wintle, A. G., and Murray, A. S. (2006). A Review of Quartz Optically Stimulated Luminescence Characteristics and Their Relevance in Single-Aliquot Regeneration Dating Protocols. Radiat. Measurements 41, 369-391. doi:10.1016/j.radmeas.2005.11.001

Wu, D., Chen, F., Li, K., Xie, Y., Zhang, J., and Zhou, A. (2016). Effects of Climate Change and Human Activity on lake Shrinkage in Gonghe Basin of Northeastern Tibetan Plateau during the Past 60 Years. J. Arid Land 8, 479-491. doi:10.1007/s40333-016-0125-5

Wu, D., Zhou, A., Zhang, J., Chen, J., Li, G., Wang, Q., et al. (2020). Temperatureinduced Dry Climate in Basins in the Northeastern Tibetan Plateau during the Early to Middle Holocene. Quat. Sci. Rev. 237, 106311. doi:10.1016/ j.quascirev.2020.106311

Xu, S. (1994). Paleosols and Their Reflection of the Environmental Changes in the Northeast Region of the Qinghai-Xizang Plateau. Chin. Geographical Sci. 14, 225-232. doi:10.13249/j.cnki.sgs.1994.03.004

Yang, K., Wu, H., Qin, J., Lin, C., Tang, W., and Chen, Y. (2014). Recent Climate Changes over the Tibetan Plateau and Their Impacts on Energy and Water Cycle: A Review. Glob. Planet. Change 112, 79-91. doi:10.1016/ j.gloplacha.2013.12.001

Yang, L., Long, H., Cheng, H., He, Z., and Hu, G. (2019). OSL Dating of a MegaDune in the Eastern Lake Qinghai basin (Northeastern Tibetan Plateau) and its Implications for Holocene Aeolian Activities. Quat. Geochronol. 49, 165-171. doi:10.1016/j.quageo.2018.02.005

Yao, T., Thompson, L., Yang, W., Yu, W., Gao, Y., Guo, X., et al. (2012). Different Glacier Status with Atmospheric Circulations in Tibetan Plateau and Surroundings. Nat. Clim Change 2, 663-667. doi:10.1038/ nclimate 1580

You, Q., Xue, X., Peng, F., Xu, M., Duan, H., and Dong, S. (2014). Comparison of Ecosystem Characteristics between Degraded and Intact alpine Meadow in the 
Qinghai-Tibetan Plateau, China. Ecol. Eng. 71, 133-143. doi:10.1016/ j.ecoleng.2014.07.022

Yu, L., and Lai, Z. (2014). Holocene Climate Change Inferred from Stratigraphy and OSL Chronology of Aeolian Sediments in the Qaidam Basin, Northeastern Qinghai-Tibetan Plateau. Quat. Res. 81, 488-499. doi:10.1016/ j.yqres.2013.09.006

Yu, X., Zhou, W., Franzen, L. G., Xian, F., Cheng, P., and Tim Jull, A. J. (2006). Highresolution Peat Records for Holocene Monsoon History in the Eastern Tibetan Plateau. Sci. China Ser. D. 49, 615-621. doi:10.1007/s11430-006-0615-y

Zhao, Y., Tzedakis, P. C., Li, Q., Qin, F., Cui, Q., and Liang, C. (2020). Evolution of Vegetation and Climate Variability on the Tibetan Plateau Over the Past 1.74 Million Years. Sci. Adv. 6. doi:10.1126/sciadv.aay6193

Zhou, L. P., Oldfield, F., Wintle, A. G., Robinson, S. G., and Wang, J. T. (1990). Partly Pedogenic Origin of Magnetic Variations in Chinese Loess. Nature 346, 737-739. doi:10.1038/346737a0

Zou, X. Y., and Wang, G. (1995). A Study on Desertification since Late Holocene in Maqu Area, Upstream of Huanghe River. J. Desert Res. 15, 65-70.
Conflict of Interest: The authors declare that the research was conducted in the absence of any commercial or financial relationships that could be construed as a potential conflict of interest.

Publisher's Note: All claims expressed in this article are solely those of the authors and do not necessarily represent those of their affiliated organizations, or those of the publisher, the editors and the reviewers. Any product that may be evaluated in this article, or claim that may be made by its manufacturer, is not guaranteed or endorsed by the publisher.

Copyright (C) 2021 Yang, Liu, Cheng, Luo, Li, Liu and Chen. This is an open-access article distributed under the terms of the Creative Commons Attribution License (CC $B Y)$. The use, distribution or reproduction in other forums is permitted, provided the original author(s) and the copyright owner(s) are credited and that the original publication in this journal is cited, in accordance with accepted academic practice. No use, distribution or reproduction is permitted which does not comply with these terms. 